\title{
Measurement and Importance Identification of Regional Systemic Risk in China
}

\author{
Pei-Nan $\mathrm{JI}^{1, \mathrm{a},{ }^{*} \text {, Li-Juan BAI }}{ }^{1}$, Yang JIANG ${ }^{1}$, Guang YU ${ }^{1}$ and Guan-Qi \\ WANG $^{1}$ \\ ${ }^{1}$ School of Management, Harbin Institute of Technology, Harbin, P.R.China, 150001 \\ jipeinan@hit.edu.cn \\ ${ }^{*}$ Corresponding author
}

Keywords: Regional risk, Systemic risk, Risk importance identification.

\begin{abstract}
Regional risk has become the focus of attention in the theoretical and practical areas in recent years, and the research on regional risk has become a hot issue. In this paper, we use all of China's A-share listed companies as the object of study, all the shares of listed companies in accordance with the provincial classification for the sub-category is divided into 31 regions. And then studies the characteristics and importance of the regional system risk in each province of our country. The following conclusions are obtained: (1) The overall systemic risk level of our country is on the rise, and the provinces with relatively high regional risk levels show the trend of shifting from inland areas to southeast coastal areas; (2) The highest importance of systemic risk is Beijing, followed by Guangdong, Zhejiang, Jiangsu and Shanghai, while the regional and institutional risks in Qinghai and Ningxia are less important. This study is of great significance to the understanding and control of regional systemic risks in China.
\end{abstract}

\section{Introduction}

On March 5, 2017, Premier Li Keqiang of the State Council once again referred to the prevention of systemic regional risks in the report of the two government work in 2017. Beginning in 2013, "the bottom line that" does not have a systemic risk of systemic risk "has been in the new year's deployment of government work reports for five consecutive years. March 2017, Liaoning Huishan dairy cliff-type collapse led to Liaoning Province and even the entire northeastern region of the financial shock and risk escalation. Also in March this year, Shandong Qixing Group billions of debt problems in Shandong Province, the emergence of regional financial risks. From the local government's position, in the face of this devastating regional risk, Liaoning and Shandong's attitude is exactly the same. As the enterprises involved in the financial enterprises and other related enterprises too many people involved in employment, but also the local focus on supporting enterprises, the government is trying to try to save. It is important and urgent to study the regional financial risk in China from the regional financial risk which is becoming more and more frequent in China.

With regard to systemic risk, the current academic community does not have a unified definition of authority, which also shows the complexity and uncertainty of systemic risk [1,2]. The second is from the point of view of the risk of infection. From the perspective of the literature at home and abroad, there are four types of definitions [3,4]. The third is defined from the perspective of financial functions [5], the fourth is defined from the impact of the real economy $[6,7]$. 
The different understanding of the definition of systemic financial risk reflects the different institutional and researcher's differences in the perspective of systemic risk research, which also leads to a large number of measurement methods for systemic risk. There are several types: First, the comprehensive index method, the comprehensive index method is based on the sub-system indicators to establish a comprehensive system of financial risk system to describe the comprehensive index method. Illing and Liu [8], Hakkio and Keeton [9], Cardarelli et al. [10] construct the financial systems of different countries or regions based on explanatory variables that measure systemic risk levels and other explanatory variables that affect systemic risks Sex risk early warning index system. Second, the early warning technology, the traditional financial crisis early warning technology research goal is through the previous financial crisis to find common ground to build early warning index system, Frankel and Rose proposed the FR probability warning model to achieve the financial crisis early warning [11]. Kaminsky, Lizondo and Reinhart proposed the KLR signaling method [12], and Kaminsky in 1999 to further improve the method, the KLR signal method has become one of the most popular early warning model. Sachs, Tornell and Velasco proposed the STV model [13], and the International Monetary Fund Andrew proposed for the crisis of developing countries in the DCSD (Developing Country Studies Division) model is an important representative of the method. Third, the network model method, the network model method is based on the interbank balance sheet mutual exposure data to study the systemic risk of the mainstream method, the main idea is through the inter-bank mutual exposure and transaction data to establish the network, according to the inter-bank market The network shape simulates the risk of mutual transmission, thus measuring the systemic risk accumulated in each bank network. The representative model of this approach is the network model established by the International Monetary Fund [14].

After the international financial crisis, China's financial risk situation has undergone great changes, and the risks of financial institutions and financial markets have been effectively controlled, but the regional financial risks have been sharply enlarged [15]. With the financial crisis after the financial institutions of individual control efforts to increase the financial institutions, the crisis gradually ease, regional risk due to lack of knowledge has gradually become a new issue of economic development. The high complexity and high infectivity of financial risks between regions makes regional risk highly devastating. On one hand, the scholars at home and abroad in their study of regional risk, are mainly from the perspective of financial institutions. Shin used the data of the financial institutions to establish the early warning mechanism of the regional wind direction, and so on. The use of the data of the financial institutions to establish the regional winds The There is little use of all the listed companies at the micro level point of view to achieve the risk of regional measurement. On the other hand, the research on the importance of systemic risk is mainly focused on the recognition of the importance of financial institutions such as banks.

\section{Methodology}

\section{Samples and data}

This paper chooses all companies listed in domestic Shanghai and Shenzhen A shares as research samples, and then removes ST companies that do not meet the conditions, and finally 3148 sample companies. And then in accordance with the company's provinces (except Hong Kong, Macao and Taiwan regions) were statistics, registered in the provinces of listed 
companies in 31 groups of data. We select the listed companies in each province for the regional regional system risk research samples, in addition to taking into account the availability of data, the listed companies on the regional economic impact and compared to non-listed companies stronger than the spread and infectivity is more important. The data of the listed companies in this paper comes from the Wind database, which selects the stock and financial data of listed companies from 2014 to May 2017.

\section{Systematic risk measurement and regional characteristics}

William F. Sharpe, Nobel laureate at Stanford University in the United States, defines microcosmic systemic risk in a paper published in 1964 and can calculate systemic risk based on his capital asset pricing model (CAPM) coefficient [16]. This paper calculates the systemic risk of each stock according to the following formula.

$$
\begin{aligned}
& r_{\alpha}=r_{f}+\beta \times\left(r_{m}-r_{f}\right) \\
& \beta=\frac{r_{\alpha}-r_{f}}{r_{m}-r_{f}}=\frac{\operatorname{Cov}\left(X_{i}, Y_{i}\right)}{\operatorname{Var}\left(X_{i}\right)}=\frac{\sum\left(X_{i}-\bar{X}\right)\left(Y_{i}-\bar{Y}\right)}{\sum\left(X_{i}-\bar{X}\right)^{2}}
\end{aligned}
$$

And: $\quad \beta$ is the system risk factor for securities

$r_{f}$ is risk-free rate of return

$r_{m}$ is market expected rate of return

$r_{a}$ is expected rate of return

$X_{i}$ is the annual growth rate of the $i$ securities

$Y$ is market index growth rate

We calculate the annual systemic risk coefficient of all A-share listed stocks based on the Capital Asset Pricing Model (CAPM). Finally, the statistical risk of all the stock system risk factors is analyzed by SPSS software, and the statistical information shown in Table 1 below is obtained.

\begin{tabular}{|c|c|c|c|c|c|}
\hline \multirow{2}{*}{ Year } & \multirow{2}{*}{$\frac{\text { Minimum }}{\text { Statistics }}$} & \multirow{2}{*}{$\frac{\text { Maximum }}{\text { Statistics }}$} & \multicolumn{2}{|c|}{ Mean } & \multirow{2}{*}{$\begin{array}{c}\text { St. dev. } \\
\text { Statistics }\end{array}$} \\
\hline & & & St. error & Statistics & \\
\hline 2014 & -1.18 & 3.04 & .6013 & .01044 & .50885 \\
\hline 2015 & -1.45 & 4.32 & .8361 & .00919 & .44832 \\
\hline 2016 & -.84 & 4.90 & 1.2377 & .00873 & .43704 \\
\hline 2017 & -.99 & 4.16 & 1.3377 & .01041 & .53120 \\
\hline \multirow{2}{*}{ Year } & Variance & \multicolumn{2}{|c|}{ Skewness } & \multicolumn{2}{|c|}{ Kurtosis } \\
\hline & Statistics & Statistics & St. error & Statistics & St. error \\
\hline 2014 & .259 & .708 & .050 & 1.854 & .100 \\
\hline 2015 & .201 & .356 & .050 & 3.320 & .100 \\
\hline 2016 & .191 & .504 & .049 & 2.654 & .098 \\
\hline 2017 & .282 & .407 & .048 & 2.108 & .096 \\
\hline
\end{tabular}

Table 1. Descriptive statistics

From Table 1 of the national A-share listed company's stock statistics, we can find: (1) from 2014 to 2017, the average of all stocks has been increasing, indicating that the systemic risk of 
listed companies in China is on the rise, The systemic risk is gradually larger; (2) from the statistics table can be found in the four-year study interval, all stocks of systemic risk distribution of the skewness is greater than 0 and the kurtosis is greater than 1 , which shows that China The overall systemic risk for the right deviation of the peak distribution.

Then we group the 3148 listed companies according to the principle of the regional grouping, and then use the market value of the listed companies as the weighted average of the provinces. The reason why the market value is chosen because the systemic risk factor we get on one hand is calculated by the stock of the tradable shares of the listed company. On the other hand, the characteristics of the non-tradable shares determine that these non-negotiable stocks are not Cause influence. Finally, we get the micro-systemic risk level of each province. The Eq. 3 is as follows:

$$
\beta_{p i}=\frac{\sum X_{i} \beta_{i}}{\sum X_{i}}
$$

And: $\quad \beta_{p i}$ is the overall systemic risk factor in i provinces

$X_{i}$ is the market value of the circulation of securities $\mathrm{i}$

$\beta_{i}$ is the systematic risk value of securities $\mathrm{i}$

According to the systematic risk of the provinces on the calculated according to the size of the risk ranking, the 31 provinces in accordance with different years were divided into relative risk level, large, medium, and small five levels and each level of the number were 7, 6, 6, 6, 6 . Then, following the time statistics, get the following scenario shown in Fig. 1. The deeper the color, the higher the relative systemic risk level.

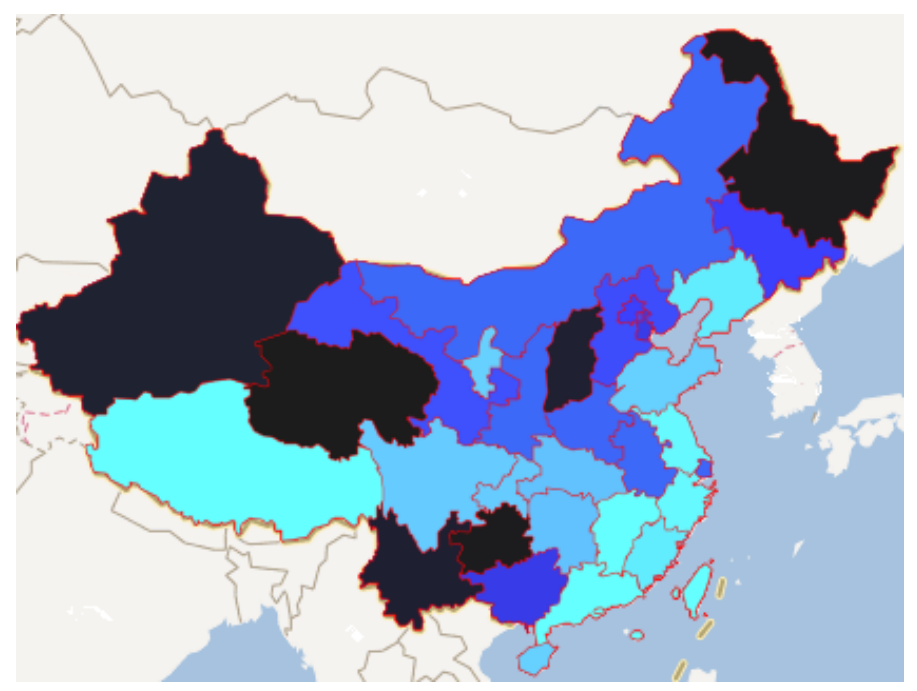

(a) 2014 


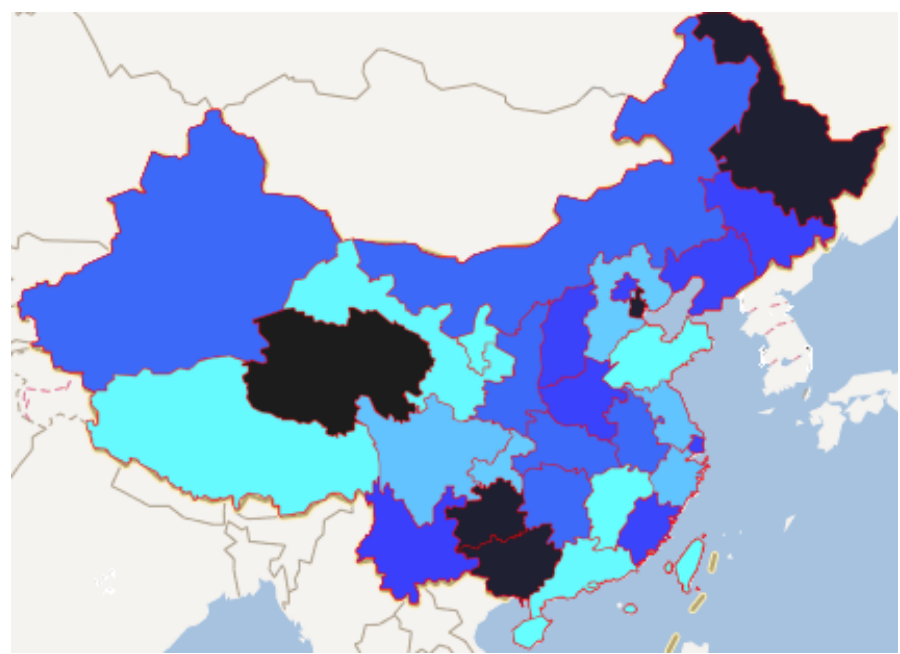

(b) 2015

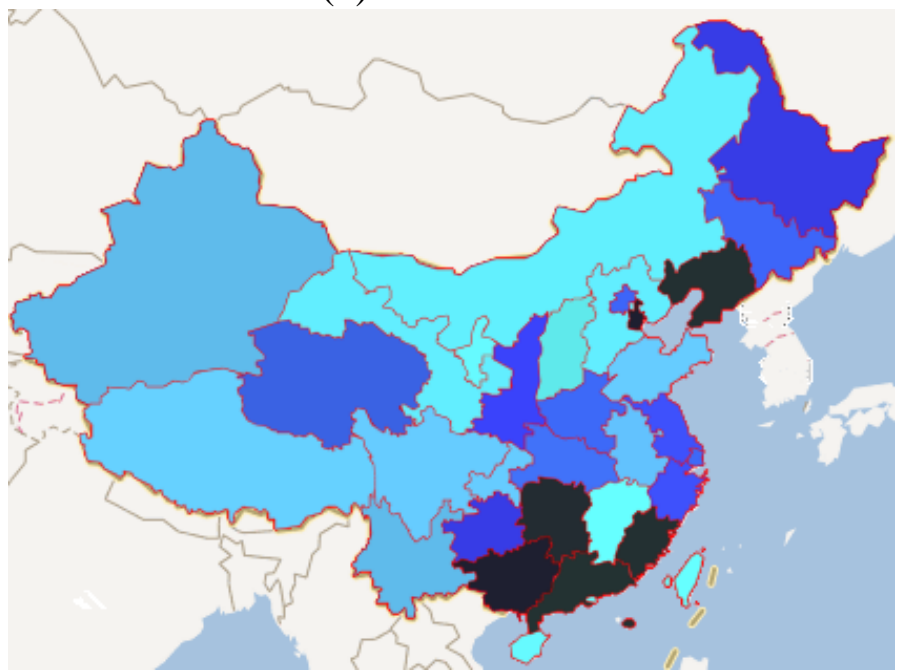

(c) 2016

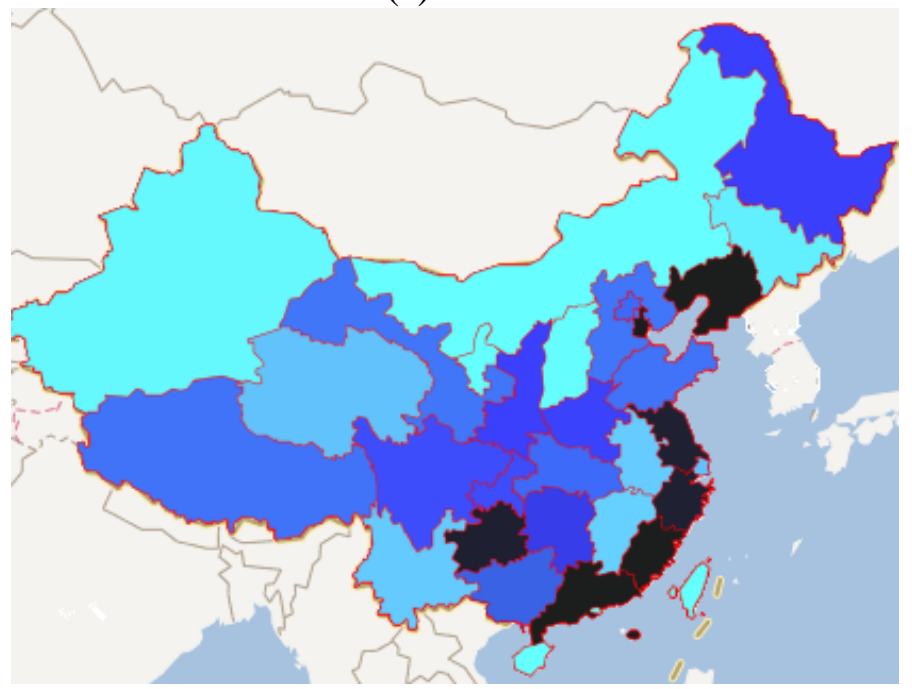

(d) 2017

Figure 1. Systematic risk changes of provinces in China during 2014 -2017 
From Fig. 1, we can find the range of the study has been in a systemic risk low (small and small) in Jiangxi province and Hainan Province, and the relative systemic risk in the high (and larger) is Tianjin, Heilongjiang and Guizhou province. The regions with relatively high level of regional system risk in China are shifting from inland areas to southeast coastal areas.

\section{Regional System Risk Importance Identification}

\section{Model}

The 2008 outbreak of the financial crisis has exposed many deficiencies in the system and the system of financial regulation, the lack of system of micro prudential supervision is also criticized a lot, only focus on the partial equilibrium of micro prudential supervision of the financial system and the individual financial institution's financial condition, no method to study the financial system from the overall balance, but did not consider external the influence of financial institutions. To this end, in 2010, the Basel Banking Regulatory Commission (BCBS) reformed the existing regulatory standards and systems and proposed additional capital requirements for systemically important financial institutions (SIFIs). So we know that the identification of the importance of the regional system risk will be important. The so-called system risk importance area means the key function in the whole system, whose bankruptcy may cause damage to the whole system and have a serious negative impact on the overall economy.

This paper studies the market volatility model of Banulescu et al., and defines the overall yield and regional yield of each province as [17] Eq. 4 and Eq. 5:

$$
\begin{aligned}
& r_{m t}=\sum \sigma_{m t} r_{i t} \\
& r_{i t}=\sigma_{i t} \rho_{m t}+\sigma_{i t} \sqrt{1-\rho_{i t}{ }^{2} \xi_{i t}}
\end{aligned}
$$

And: $r_{m t}$ is overall market rate of return

$r_{i t}$ is regional rates of return in provinces

$\sigma_{m t}, \sigma_{i t}$ is the SD of the regional conditions between the whole and each province

$\rho_{m t}, \rho_{i t}$ is regional time-varying correlation coefficients of the whole and each province

The overall risk of this paper is measured by the expected loss (ES), and the expected loss is defined as the market return of the system, and the expected return of the system under the condition of RMT below the threshold value of C. Then from Su Mingzheng, Zhao Jinwen the component loss method (CES) system importance model, this method is a measure of the weight of individual financial institutions market changes, changes in the overall risk system, namely the individual financial institutions overall contribution to systemic risk, the expression is as follows [18]:

$$
\begin{aligned}
& E S_{m, t-1}(C)=-E_{t-1}\left(r_{m t} \mid r_{m t} \prec C\right) \\
& \mathrm{CES}_{\mathrm{it}}=\varpi_{\mathrm{it}} \frac{\partial \mathrm{ES}_{\mathrm{m}, \mathrm{t}-1}(\mathrm{C})}{\partial \varpi_{\mathrm{it}}}
\end{aligned}
$$

And: $\omega_{\text {it }}$ is regional weights for each province 
Then according to the above calculation formula, the following deduction is made:

$$
\begin{aligned}
& C E S_{i t}=\omega_{i t} M E S_{i t}(C)=\varpi_{i t} E_{t-1}\left(r_{i t} \mid r_{m t} \prec C\right) \\
& =\omega_{i t} \sigma_{i t} E_{t-1}\left\langle\varepsilon_{i t} \mid \varepsilon_{m t} \prec C / \sigma_{m t}\right\rangle \\
& =\omega_{i t} \sigma_{i t} E_{t-1}\left(\rho_{t} \varepsilon_{m t}+\sqrt{1-\rho_{t}^{2}} \xi_{i t} \mid \varepsilon_{m t} \prec C / \sigma_{m t}\right) \\
& =\omega_{i t}\left[\begin{array}{l}
\sigma_{i t} \rho_{i t} E\left(\varepsilon_{m t} \mid \varepsilon_{m t} \prec C / \sigma_{m t}\right)+ \\
\sigma_{i t} \sqrt{1-\rho_{i t}^{2}} E_{t-1}\left(\xi_{i t} \mid \varepsilon_{m t} \prec C / \sigma_{m t}\right)
\end{array}\right]
\end{aligned}
$$

We can see from the above, the single regional systemic risk components of the expected loss rate of $\sigma \mathrm{mt}$ and $\sigma \mathrm{it}$, the fluctuation of $\omega \mathrm{it}$, a single region and the combination weight of the overall market time-varying correlation coefficient $\rho$ it and the tail of individual financial institutions and the market portfolio is expected to constitute.

\section{Result}

In this paper, we calculate the regional fluctuation in the provinces of ratio it by the provinces listed company monthly stock price standard deviation weighted average, while the overall volatility sigma MT by the provinces of the volatility of the weighted average weight, which we use for the provinces listed companies in market capitalization. The correlation coefficient of the market capitalization of listed companies related coefficient it through A-share listed companies in market capitalization of all provinces in China and the whole of the said. We selected the interval of stock market data are from 2014 to 2015 May the stock data, data from database vendors. Finally, using the nonparametric method proposed by Scaillet to calculate the expected loss of market portfolio and agency, the estimation formula is as follows [19]:

$$
\begin{gathered}
E\left(\varepsilon_{m t} \mid \varepsilon_{m t} \prec C\right)==\omega_{t} \frac{\sum_{t=1}^{T} \varepsilon_{m t} \phi\left(\frac{c-\varepsilon_{m t}}{h}\right)}{\sum_{t=1}^{T} \phi\left(\frac{c-\varepsilon_{m t}}{h}\right)} \\
E\left(\xi_{m t} \mid \varepsilon_{m t} \prec C\right)==\omega_{t} \frac{\sum_{t=1}^{T} \xi_{m t} \phi\left(\frac{c-\varepsilon_{m t}}{h}\right)}{\sum_{t=1}^{T} \phi\left(\frac{c-\varepsilon_{m t}}{h}\right)}
\end{gathered}
$$

In Eq. 9 and Eq. 10, $\mathrm{c}=\mathrm{C} / \sigma_{\mathrm{mt}}$ is the threshold value, and $h$ is bandwidth, $\Phi$ for the teenage boy conditional density function, $\mathrm{h}=\mathrm{T}^{-0.2}$ and $\mathrm{C}$ is the $5 \%$ quantile of market return distribution.

From the above calculations, we obtain the contribution of the systematic risk contribution as shown in the following table and the contribution of the regional system risk, and then sort them to the results shown in Table 2, as shown in the table. 
Table 2. The importance of regional systemic risk in China

\begin{tabular}{cccc}
\hline Region & CES & Systemic risk contribution & Ranking \\
\hline Beijing & 1.71988 & $27.584 \%$ & 1 \\
Guangdong & 1.01423 & $16.267 \%$ & 2 \\
Zhejiang & 0.51345 & $8.235 \%$ & 3 \\
Jiangsu & 0.50547 & $8.107 \%$ & 4 \\
$\ldots$ & $\ldots$ & $\ldots$ & $\ldots$ \\
Xizang & 0.02584 & $0.414 \%$ & 28 \\
Yunnan & 0.02402 & $0.385 \%$ & 29 \\
Ningxia & 0.01842 & $0.295 \%$ & 30 \\
Qinghai & 0.01757 & $0.282 \%$ & 31 \\
\hline
\end{tabular}

From Table 2 we can see that China's provinces regional system risk importance is the highest in Beijing, with the systemic risk of $27.584 \%$, followed by Guangdong, Zhejiang, Jiangsu and Shanghai, the system risk contributions were $16.267 \%, 8.235 \%, 8.107 \%$ and $6.867 \%$, and a regional system for the lowest risk importance Qinghai and Ningxia, the contribution of the systemic risk was $0.282 \%$ and $0.295 \%$ respectively.

\section{Conclusion}

From the micro level of Listed Companies in China, this paper studies the characteristics and importance of systemic and regional systemic risks in china. Study on the risk characteristics of systemic risk and regional system of China's listed companies with the capital asset pricing model and the descriptive statistical analysis found that China's overall level of systemic risk showed a rising trend of regional system risk is relatively important areas emerged from the inland areas to the southeast coastal transfer trend, the economy the total amount of more and more widely in the relative influence of worthy of attention. Then, using the component loss method (CES) model to study the importance of the relative importance of system risk in the provinces of region of our country, the regional systemic risk contribution and regional order, has a strong reference for the prevention and management of China's regional risk control system.

\section{Acknowledgement}

This research was financially supported by the National Natural Science Foundation of China under Grant No.71531013; 71490720; 71401047.

\section{References}

[1] P. Bartholomew, G. Whalen, Fundamentals of systemic risk, Research in financial services: Banking, financial markets, and systemic risk. 7 (1995) 3-18.

[2] F. S. Mishkin, Understanding financial crises: a developing country perspective: National Bureau of Economic Research, 1996.

[3] G. G. Kaufman, K. E. Scott, What is systemic risk, and do bank regulators retard or contribute to it? The Independent Review, 7(3) (2003) 371-391. 
[4] S. E. Lee, E. C. Olsen, W. W. Wierwille, A comprehensive examination of naturalistic lane-changes: United States, National Highway Traffic Safety Administration, 2004.

[5] R. Levine, Financial development and economic growth: views and agenda, Journal of economic literature. 35(2) (1997) 688-726.

[6] B. IMf, Guidance to Assess the Systemic Importance of Financial Institutions, Markets and Instruments: Initial Considerations, 2009.

[7] O. De Bandt, P. Hartmann, Systemic risk: a survey, 2000.

[8] M. Illing, Y. Liu, An index of financial stress for Canada, Bank of Canada Ottawa, 2003.

[9] C. S. Hakkio, W. R. Keeton, Financial stress: what is it, how can it be measured, and why does it matter? Economic Review-Federal Reserve Bank of Kansas City. 94(2) (2009) 5.

[10] M. S. Lall, M. R. Cardarelli, S. Elekdag, Financial stress, downturns, and recoveries, International Monetary Fund, 2009.

[11] J. A. Frankel, A. K. Rose, Currency crashes in emerging markets: An empirical treatment. Journal of international Economics. 41(3-4) (1996) 351-366.

[12] G. Kaminsky, S. Lizondo, C. M. Reinhart, Leading indicators of currency crises, Staff Papers. 45(1) (1998) 1-48.

[13] J. Sachs, A. Tornell, A. Velasco, Financial crises in emerging markets: the lessons from 1995: National bureau of economic research, 1996.

[14] E. BIS, Handbook on Securities Statistics, Part1: Debt securities issues, 2009.

[15] L. SONG, Y. YE, The Study of Macro-financial Risk of Chinese Real Estate Industry_-From Financial Stability Perspective, Economic Management. 32(12) (2010) 34-39.

[16] W. Lahmann, C. Kaserer, Measuring systemic risk and assessing systemic importance in global and regional financial markets using the ess-indicator, 2011.

[17] N. Banulescu-Bogdan, The role of civil society in EU Migration Policy: perspectives on the European Union's Engagement in its neighbourhood, Migration Policy Institute, Washington DC, 2011.

[18] S. Mingzheng, Z. Qingjun, Z. Jinwen, The Assessment and Influencing Factor Analysis of Systemic Importance of Listed Commercial Banks in China: Based on the Perspective of the Decomposition of Expected Shortfall, Nankai Economic Studies. 3 (2013) 9.

[19] O. Scaillet, A Kolmogorov-smirnov type test for positive quadrant dependence, Canadian Journal of Statistics. 33(3) (2005) 415-427. 